HUNGARIAN AGRICULTURAL ENGINEERING

$N^{\circ} 28 / 2015$ 15-18

Published online: http://hae-journals.org/

HU ISSN 0864-7410 (Print) / HU ISSN 2415-9751(Online)

DOI: $10.17676 / \mathrm{HAE} .2015 .28 .15$
PERIODICAL OF THE COMITTEE OF AGRICULTURAL AND BIOSYSTEM ENGINEERING OF

THE HUNGARIAN ACADEMY OF SCIENCES and

SZENT ISTVÁN UNIVERSITY

Faculty of Mechanical Engineering

\title{
EXAMINATION THE EFFECTIVENESS OF FLOW CONTROL IN A SOLAR SYSTEM
}

\author{
Author(s): \\ P. Víg - I. Seres
}

\author{
Affiliation: \\ Department of Physics and Process Control, Szent István University, Páter K. u. 1., Gödöllö, H-2103, Hungary
}

Email address:

vig.piroska@gek.szie.hu, seres.istvan@gek.szie.hu

\begin{abstract}
The present paper examines the benefits of the flow rate control compared with traditional on-off switch-control in case of solar water heating system. The optimal volumetric flow rate of the solar fluid depending on the radiation and the stored water temperature. This flow rate is realized with controlling the frequency of the pump by an ALTIVAR 31 frequency inverter. The paper presents and summarizes the calculated results based on measurement data obtained during the operation with these regulations.
\end{abstract}

\section{Keywords}

solar energy, solar thermal system, flow rate, control, efficiency

\section{Introduction}

In the recent times the photovoltaic energy utilization of the solar applications get bigger importance due to the improvement of the photovoltaic technology and to the coming out of cheap PV modules. The guaranteed grid access and the feed-in tariffs help the spreading as well. Due to the spread of the PV technology, the development of the efficiency of the solar thermal systems get smaller significance. The present work is dealing with the improvement of a solar thermal system by examining the efficiency of a flow rate control method.

The dependence of the efficiency of the solar thermal system on the flow rate was investigated by a lot of researcher. In the homepage of the Build it Solar [1] there is an analysis of the efficiency dependence of flat plate collectors as a function of the flow rate. They concluded, that the bigger flow rate cause bigger efficiency, however they stress, that for the bigger flow rate higher pump power and - for keeping the laminar flow - bigger tube diameters have to be used, which increases the installation and maintain costs. Furbo and Shah [2] for SDHW systems determined an 0.2 to 0.3 liter $/ \mathrm{min} / \mathrm{m}^{2}$ solar collector ideal flow rate for the optimal operation.

Kar [3] determined the optimal flat-plate collector mass flow rate by maximizing the exergy delivery of the collector as the objective function. Badescu [4] gave an optimal control of flow in solar collector system in case of fully mixed water storage tanks. Yousefi et al. [5] stated, that in case of low flow rates, by increasing the flow rate, the collector and the system efficiency is increased as well.

The control is an important influencing factor from the aspect of the efficiency of a heating system. In the modern heating systems the flow rate control of the heating circuit pump (intelligent pump) is spreading for achieving the optimal heating medium temperature. This indicated the idea, that we should study the effectiveness of the flow control for a vacuum tube system, too.

Víg and Farkas [6] studied the vacuum tube collector efficiency vs the pump flow rate, and they concluded, that the optimal values, which are function of the stored water temperature and the solar radiation not necessarily can be achieved at the maximum flow rate. That is it can be useful to operate a system at optimal flow rate under the given conditions, such as to establish a flow control.

The possible advantages of such a control was studied by Péter Vladár [7] in his diploma thesis by using TRNSYS models. The PID control was calculated to results maximum $20 \%$ energy surplus. These reassuring results gave basics for realizing the flow control and checking the theoretical results in practice.

\section{System description}

The studied system is installed in the Department of Physics and Process Control, Szent István University, Gödöllő, Hungary. On the site of the solar system a meteorological station was installed, too. The collector of the system includes 15 vacuum tubes, the absorber area (noted by A in the model) is $1.22 \mathrm{~m}^{2}$. The solar fluid collector outlet temperature is noted by Tout. The area of solar loop inside heat exchanger is $1.4 \mathrm{~m}^{2}$, the specific heat capacity of solar fluid is $3194 \mathrm{~J} / \mathrm{kgK}$.

The volume of the solar storage tank is 3001 , it is covered with 5 $\mathrm{cm}$ thick insulating layer. The stored water temperature can be measured in 3 layers: bottom (Tsb), middle (Tsm), and top (Tst), the average water temperature is Ts. The measurement of solar radiation is located in the plane of the collector with pyranometer. Figure 1. shows the vacuum tube collector and storage tank of the system.

The flow rate control in the solar loop was realized with control of existing pump of the system by installing an ALTIVAR3 1 frequency inverter. The regulation is based on the measured data in every $10 \mathrm{~s}$, the data are recorded to the hard drive. The essence of on-off switch-control: if the difference between temperature of solar fluid in the collector outlet and the stored water in the 
middle layer of the storage is at least $5{ }^{\circ} \mathrm{C}$, the pump works with maximum power, otherwise switched off, while during the flow rate control, if this temperature difference less than $5{ }^{\circ} \mathrm{C}$, the flow rate decreases linearly.

During the measurement of temperatures Pt100 resistance thermometer and thermocouple were used. The solar fluid is polipropylen-glycol and distilled water in $50-50 \%$. The pump normally working with 3 constant power: 35,40 and $50 \mathrm{~W}$. The main parts of control system, the pump and the frequency regulator are shown in Figure 2.
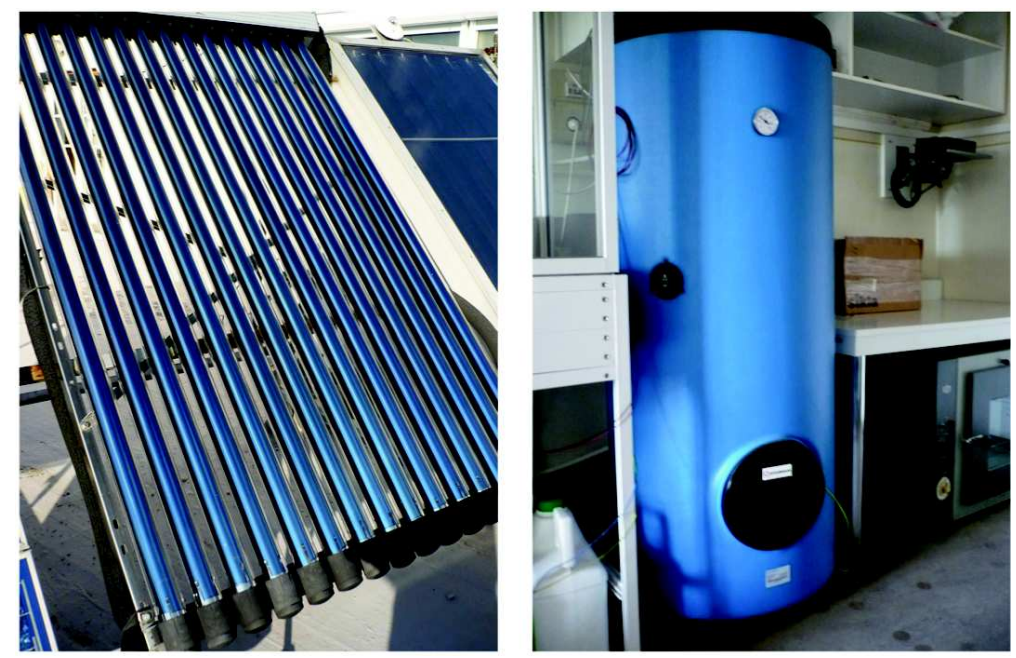

Figure 1. Main parts of the system: collector and storage tank
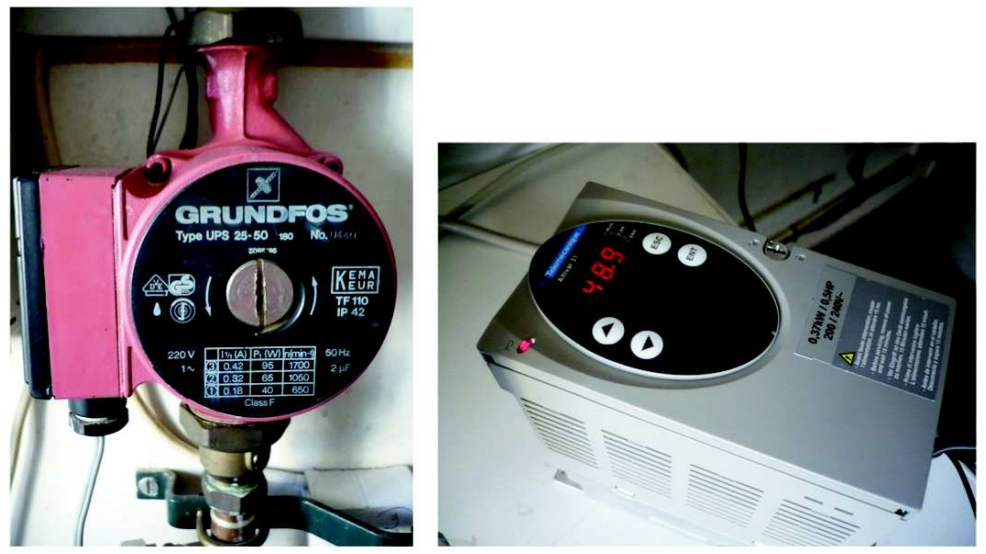

Figure 2. Pump and frequency regulator

The installation of the regulator in the system, the development of communications with data acquisition ADAM modules and the Labview program which generates the control signal are detailed in another paper.

\section{Data gathering}

Two system operations are compared: the on-off control and flow rate control. The necessary measurement data were gathered from 1 July 2015. Till August 10 the system worked with on-off control and from August 11 it was operated with flow control.

The flow and heat losses of the collector and the solar tank are negligible due to the good insulation. The heat losses in the long $(2 * 25 \mathrm{~m})$ tubing between the collector and the storage are considerable, but as these losses are very similar for the two compared cases, during the comparison they are not important.

It is important to mention for the stratification of the water in the tank, that the warm solar liquid enter in the middle of the tank to the heat exchanger and it exist at the bottom of it. Because of it the temperature of the middle layer temporarily can be higher than the upper layer temperature during continuous operation. The layer temperatures are normalized for the end of the day.
Figure 3 and Figure 4 show typical measurement data rows for the two different control. Figure 3 shows the results of the flow control in case of the variably cloudy day. The upper part of the figure shows the collector outlet temperature (Tout), and the temperatures in the 3 layers of the storage tank. The second graph shows the solar radiation, the third shows the control signal (ToutTsm) and forth shows when the pump was on in 7th of September.

It can be seen well, that when the solar radiation is fluctuating, the solar liquid temperature for only short time was higher with 5 degrees than the temperature of stored water in the middle layer. In addition the flow rate control decreased the effect of the fluctuations in the radiation.

Figure 4 shows the graphs of the typical example for the onoff switch-control, the graphs type and markings are similar than Figure 3.

Transient time (tTR) is the sum of minutes, when the pump onoff status changing in the next minute. It can be seen, that, this indicator is short during the flow rate control and remarkable in case of on-off control. 

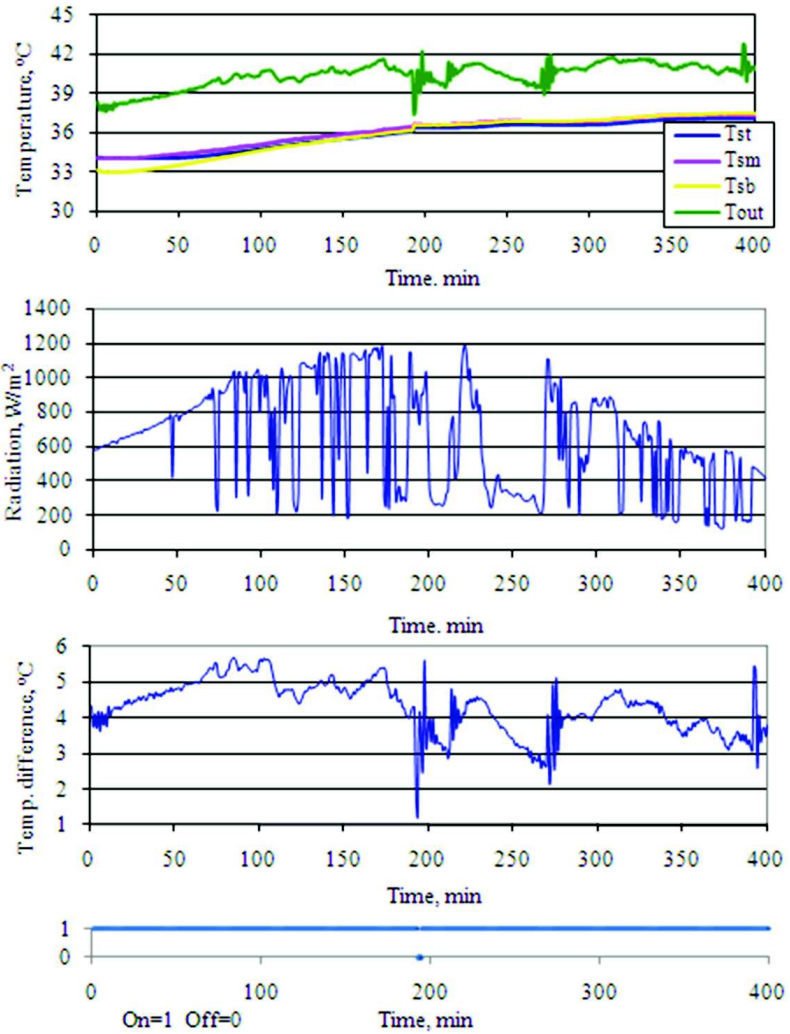

Figure 3. Results with flow rate control

\section{Analysis of the measurement results}

For the numerical comparison of the efficiency of the controls, the following concepts and relationships have been used:

Daily working time $\left(\mathrm{t}_{\mathrm{w}}\right)$ is the time between the first on and last off switch of pump in the day.

Not transient part (noTR):

$$
\operatorname{noTR}=\left(1-\frac{t_{T R}}{\mathrm{t}_{\mathrm{w}}}\right) * 100
$$

Daily collected heat energy:

$Q=c_{v} *\left(T_{S E}-T_{S B}\right) * m+\sum c_{v} * \dot{m}_{L} *\left(\mathrm{~T}_{\mathrm{st}}-\mathrm{T}_{\mathrm{sb}}\right) * \tau$

where $c_{v}$ is specific heat capacity of water, the stored water average temperature at the end $\left(\mathrm{T}_{\mathrm{sE}}\right)$ and at the beginning $\left(\mathrm{T}_{\mathrm{sB}}\right)$ of day, $\mathrm{m}=300 \mathrm{~kg}$, the mass of stored water, $\dot{\mathrm{m}}_{\mathrm{L}}$ is mass flow of hot water load, $\tau$ is unit of time (one minute).

The efficiency of the system is the rate of daily gathered solar energy and energy come from solar radiation $\left(\mathrm{I}_{t}\right)$ :

$$
\eta=\frac{Q}{\sum I_{t} * A * \tau}
$$

For quantifying the thermal stratification the dimensionless quantity (ST) has been introduced where $\mathrm{n}$ is the number of time units which the summary applies. This value in case of mixed storage is 0 , and growing when improving the stratification.

$$
S T=\frac{1}{n} \sum \frac{\mathrm{T}_{\mathrm{st}}-\mathrm{T}_{\mathrm{sb}}}{T_{S}} * 1000
$$

Pump daily average power:

$$
P_{p, a v g}=\frac{1}{n} \sum \frac{\dot{m}}{\dot{m}_{\max }} * P_{\max }
$$
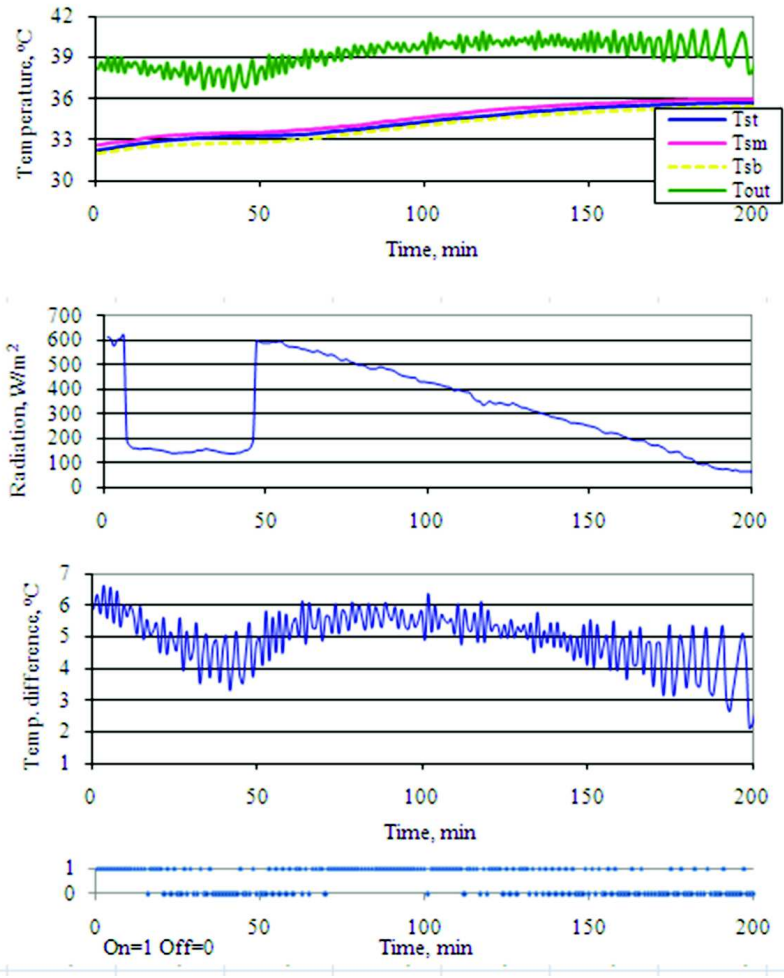

Figure 4. Example for on-off control (2015. 08. 06.)

where $\dot{\mathrm{m}}$ is the actual mass flow, $\dot{\mathrm{m}}_{\max }$ is the maximal mass flow in the collector loop.

\section{Results}

For the comparison of the two control method, daily periods without hot water consumption were used, and the comparison was made between such intervals, when the average radiation was almost the same $\left(548.3 \mathrm{~W} / \mathrm{m}^{2}\right.$ ill. $\left.552.5 \mathrm{~W} / \mathrm{m}^{2}\right)$ and the temperature of the initial temperature of the stored water was about the same, too. The values are presented in Figure 5.

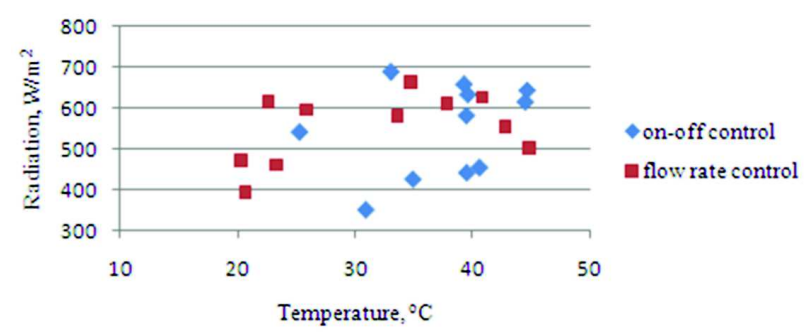

Figure 5. Initial temperatures and average radiations for calculations

In Figure 6. the values of the efficiency, the thermal stratification and the dimensionless ST and the pump working time rate is shown. The numerical values of the graphs are presented in Table 1. For the comparison of the pumps energy need, some data can be seen about ratio of the working time of the pump compared to the total time.

The numerical data show, that in the investigated time period, under the given conditions the system efficiency was $13 \%$ higher, and the thermal stratification by $64 \%$, and the length of nontransient periods by $37 \%$ was higher under the flow control, compared to the On-Off switch method. 
It can be concluded, that the daily working time significantly was increased (by $50 \%$ ), but the pump power just went up by 5.3 W.

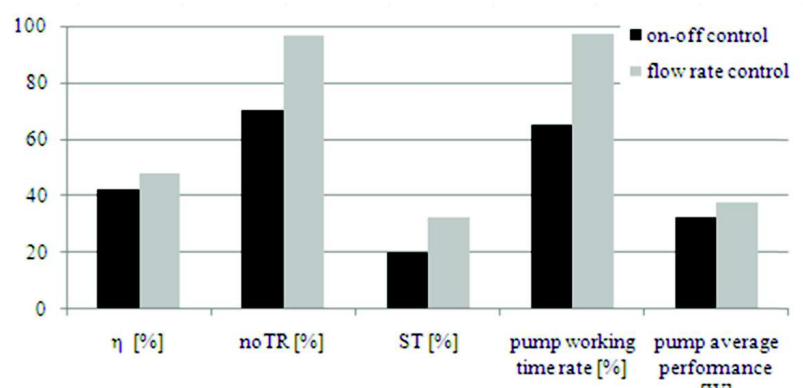
[W]

Figure 6. Results for comparison the two controls

Table 1. Calculated results during several controls

\begin{tabular}{|l|c|c|c|}
\hline & $\begin{array}{c}\text { On-off } \\
\text { control }\end{array}$ & $\begin{array}{c}\text { Flow rate } \\
\text { control }\end{array}$ & $\begin{array}{c}\text { Surplus } \\
{[\%]}\end{array}$ \\
\hline$\eta,[\%]$ & 42.43 & 48.03 & 13.2 \\
\hline ST, [-] & 19.87 & 32.63 & 64.2 \\
\hline No TR, [\%] & 70.37 & 96.72 & 37.4 \\
\hline Pump working time rate, [\%] & 65.35 & 97.45 & 49.1 \\
\hline Pump average power, [W] & 32.66 & 37.93 & 16.1 \\
\hline
\end{tabular}

\section{Conclusions}

It can be stated, that the results, achieved from the measurement data, agree well with the results of the modelling [7]. The advantages of the flow control against the on-off switch can be recognized mainly during the morning system start, during the evening system shutdown and during cloudy conditions or when the water temperature is higher in the tank.

The aim of the paper was to determine if there is measurable difference in the efficiencies for the two control methods. To do this regulation by an intelligent pump can cause high expenses. To reduce the costs we borrowed a frequency inverter, which is a multifunctional, wide range usable device. For a solar system the pump power is relatively low $(40-50 \mathrm{~W})$, a much simpler and cheaper solution can be done as well, and as in this case the cost of the installation and operation is much lower, so it is worth to install.

As a continuation of our work, the building and the installation of such a circuit is planned.

\section{Acknowledgements}

The authors would like to thanks the help of the Schneider Electric Hungária Villamossági Zrt for the free replacement of our faulted frequency regulator, and in this way supporting the research.

\section{References}

[1.] Builditsolar, 2014. Determining collector flow rate, http://www.builditsolar.com/References/ColFlowRate.htm

[2.] Furbo S., Shah L. J. 1996. Optimum solar collector flow rates, EuroSun '96, München, DGS Sonnenergie Verlags, pp. 189- 193.

[3.] Kar A. K.: 1989. Exergy optimization of flow rates in flatplate solar collectors, International Journal of Energy Research, Volume 13, Issue 3, pages 317-326.

http://dx.doi.org/10.1002/er.4440130308

[4.] Badescu V.: 2008. Optimal control of flow in solar collector system with fully mixed water storage tanks, Energy Conversion \& Management, 49, pp.169-184.

http://dx.doi.org/10.1016/j.enconman.2007.06.022

[5.] Yousefi T., Veysi F., Shojaeizadeh E., Zinadini S.: 2012.

An experimental investigation on the effect of A12O3-H2O nanofluid on the efficiency of flat-plate solar collectors, Renewable Energy, Volume 39, Issue 1, March 2012, pp. 293298. http://dx.doi.org/10.1016/j.renene.2011.08.056

[6.] Víg P., Farkas I.: 2013. Effect of volumetric flow rate on energy production of vacuum tube solar collector, Mechanical Engineering Letters, vol.10, pp. 102-110.

[7.] Vladár P.: 2014. Thesis, Faculty of Mechanical Engineering, Szent Istvan University, Gödöllő, Hungary 